\title{
Impact Behaviour of Aluminum Particles upon Aluminum, Magnesium, and Titanium Substrates using High Pressure and Low-Pressure Cold Spray
}

(Kelakuan Kesan Zarah Aluminum ke atas Substrat Aluminum, Magnesium dan Titanium menggunakan Semburan Sejuk Tekanan Tinggi dan Tekanan Rendah)

\author{
Abreeza Manap*, Savisha Mahalingam, Siti Nurul Akmal Yusof, Nurfanizan Afandi \& Huda
}

ABDULLAH

ABSTRACT

This study is focused on the impact and residual stress behaviour of aluminum component repair using aluminum powder via two different types of cold spray processes; high pressure cold spray (HPCS) and low-pressure cold spray (LPCS). It has been carried out via smoothed particle hydrodynamics simulations, comparing aluminum substrate with other lightweight materials such as titanium and magnesium. The obtained results have shown that the impact behaviour is influenced by velocity, porosity, deformation behaviour, flattening ratio, total energy and maximum temperature. The aluminum particles impacting on aluminum substrates using LPCS is slightly deformed, with the smallest flattening ratio leading to less pore formation between the particles. This has subsequently resulted in good coating quality. Furthermore, HPCS has contributed greatly to the deposition of particles on the heavier and harder substrate, such as titanium substrate. Thus, the overall result indicates that LPCS is better for repairing aluminum component compared to HPCS.

Keywords: Aluminum; high pressure cold spray; impact behaviour; low-pressure cold spray; residual stress

ABSTRAK

Kajian ini difokuskan pada impak dan tingkah laku tekanan sisa pembaikan komponen aluminum menggunakan serbuk aluminum melalui dua jenis proses penyemburan sejuk; semburan sejuk tekanan tinggi (HPCS) dan semburan sejuk tekanan rendah (LPCS). Ia telah dilakukan melalui simulasi hidrodinamik zarah halus, membandingkan substrat aluminum dengan bahan ringan lain seperti titanium dan magnesium. Hasil yang diperoleh menunjukkan bahawa tingkah laku impak dipengaruhi oleh halaju, keliangan, tingkah laku ubah bentuk, nisbah meratakan, jumlah tenaga dan suhu maksimum. Zarah aluminum yang mempengaruhi substrat aluminum menggunakan LPCS sedikit cacat, dengan nisbah meratakan terkecil yang menyebabkan pembentukan liang antara zarah-zarah tersebut. Ini kemudiannya menghasilkan kualiti salutan yang baik. Tambahan pula, HPCS telah banyak menyumbang kepada pemendapan zarah pada substrat yang lebih berat dan keras, seperti substrat titanium. Oleh itu, hasil keseluruhan menunjukkan bahawa LPCS lebih baik untuk memperbaiki komponen aluminum berbanding HPCS.

Kata kunci: Aluminum; semburan sejuk tekanan tinggi; semburan sejuk tekanan rendah; tekanan sisa; tingkah laku impak

\section{INTRODUCTION}

Since the past few decades, the world has been facing the imminent challenge of global warming caused by greenhouse gases (GHGs) emission. Carbon dioxide $\left(\mathrm{CO}_{2}\right)$ is the predominant GHGs emitted due to human activities. Naturally created by burning huge amounts of fossil fuels, it leads to extreme climate change (Houghton et al. 2001), which is a fundamental threat to the biological systems and physical systems, affecting regional and global climate. Therefore, this crisis has spurred efforts to address them by developing a new lightweight material that works by reducing $\mathrm{CO}_{2}$ emissions as a control method to decrease fuel consumption. Since the transportation sector is one of the major contributors of GHGs, lightweight metals like aluminum, titanium and magnesium have been applied tremendously in the sector to reduce the emissions.

Aluminum is well known as a non-ferrous metal having high corrosion resistance, low density and high strength-to-weight ratio (Bahmani et al. 2019; Ogawa et al. 2008). It is widely used in automotive engines (Blindheim et al. 2019) due to weight reduction, which 
results in reduced fuel consumption and consequent global impact. However, defects may occur in its components due to its high susceptibility towards cracking (Ogawa et al. 2008), corrosion (Andreatta et al. 2004; Dzhurinskiy et al. 2012), and wear (Attia et al. 2011). Primary aluminum production will cause further increments in GHGs emission to the environment, thus rendering component repairing as an effective way to lessen the global impact on the environment. This will allow reduced energy consumption and costs, as repairing the components costs less than by replacing them with new ones.

Various repairing methods like welding and thermal spray have been utilized extensively in the past. However, severe difficulty has been encountered in establishing and controlling the optimum spraying conditions. Therefore, cold spray (CS) technique is a new approach towards repairing all defects found in lightweight materials, such as aluminum, titanium and magnesium. CS upstages other conventional techniques owing to its low temperature operation, which minimizes potential phase transformation by keeping the particles in the unmodified solid state (Manap et al. 2019).

In general, there are two types of CS processes, which are known as high pressure cold spray (HPCS) and low-pressure cold spray (LPCS). Extensive researches (Manap et al. 2018a, 2018b; Schmidt et al. 2006; Wong et al. 2013) carried out have focused on HPCS via numerous simulation and experimental procedures. It is acknowledged to be capable of successfully repairing a wide range of materials, such as nickel, copper, Inconel, and stainless steel, as well as extremely hard metal like tungsten. However, it also poses a limitation, specifically difficult application in aluminum repairing via dimensional error execution when attempting mold repair (Lee et al. 2007). Hence, LPCS has gained more attention (Champagne \& Helfritch 2016) as it is capable of repairing aluminum components using aluminum powder. Furthermore, it also allows the deposition of thick metal coatings, suitable for use in repair and shape modification of molds. However, LPCS works with lightweight components only.

Therefore, it is important to study the impact behaviour and residual stress of HPCS and LPCS on different lightweight components in investigating aluminum repair. It can be carried out smoothly using simulation rather than via experiment, as a longer duration of the deposition process can only be obtained by simulation method. Moreover, full understanding regarding LPCS deposition is a task that can be achieved with much ease using numerical simulation compared to the experimental procedures. Thus, numerical simulation is deemed as the best method to elucidate CS behaviour and residual stress on different lightweight components.

A comparative study on aluminum component repair has been attempted in this research by using different lightweight materials that are lighter and heavier than aluminum. Aluminum is lighter by $63 \%$ per unit volume (Dong 2010) compared to titanium, and $36 \%$ heavier than magnesium. Hence, magnesium and titanium components have been chosen to compare aluminum repair using HPCS and LPCS. This work aims to study the impact behaviour and residual stress of aluminum particles impacting on different lightweight substrates (components), such as aluminum, titanium and magnesium, using smoothed particle hydrodynamics (SPH) simulation. The impact behaviour has been subsequently analyzed by evaluating deformation behaviour, porosity, total energy and maximum temperature.

\section{MATERIALS AND METHODS}

The numerical simulation has been written in FORTRAN77 and compiled in GFORTRAN COMPILER using Cygwin64 Terminal. The SPH simulation analysis has modelled multiple particle impact of CS, followed by HPCS and LPCS modelling via modification of the parameters and Johnson-Cook visco model plasticity (Ogawa et al. 2008). A list of material properties at room temperature used in the SPH simulation is given in Table 1.

\section{SPH METHOD}

SPH is typically used to simulate the fluid flow in solving the problem in computational continuum dynamics. The partial differential equations are changed into integral equations by an interpolation function, which gives the kernel estimation of the field variables at a point. The discrete kernel estimation can be calculated by considering a function $f$ as in (1).

$$
\langle f(x)\rangle \cong \sum_{i=1}^{N} m_{i} f_{i} W\left(\frac{\left|x-x^{\prime}\right|}{h}\right) / \pi
$$

where $f$ is the arbitrary function of three-dimensional position vector $x$; $W$ is the smoothing kernel with a width influenced by the parameter; $h$ which is the smoothing length; and $i$ is the finite volume particle. 
TABLE 1. The material properties of aluminum, magnesium and titanium used in SPH simulation

\begin{tabular}{lccc}
\hline \multicolumn{1}{c}{ Properties (unit) } & \multicolumn{2}{c}{ Material } \\
\cline { 2 - 4 } & Aluminium & Magnesium & Titanium \\
\hline Density, $\rho\left(\mathrm{kg} / \mathrm{m}^{3}\right)$ & 2710 & 1.738 & 4520 \\
Young's modulus, $G(\mathrm{GPa})$ & 68.9 & 17 & 116 \\
Poison's ratio & 0.33 & 0.281 & 0.34 \\
Heat capacity $(\mathrm{J} / \mathrm{kg} / \mathrm{K})$ & 904 & 1020 & 528 \\
Melting temperature, $T_{\text {melt }}(\mathrm{K})$ & 916 & 923 & 1650 \\
Yield stress, $A$ (MPa) & 148.4 & 532 & 806.6 \\
Hardening constant, $B(\mathrm{MPa})$ & 345.5 & 229 & 481 \\
Hardening exponent, $n$ & 0.183 & 0.032 & 0.319 \\
Strain rate constant, $C$ & 0.001 & 0.0294 & 0.019 \\
Thermal softening exponent, $m$ & 0.895 & 1.00 & 0.655 \\
Reference temperature, $T_{\text {ref }}(\mathrm{K})$ & 300 & 300 & 300 \\
Reference strain rate & 1.338 & 1.38 & 1.536 \\
Grüneisen parameter $\Gamma$ & 2 & 5920 & 1.23 \\
Intercept Us-Up curve $(\mathrm{m} / \mathrm{s})$ & 5386 & 1.07 & 3573 \\
Slope Us-Up curve, & & & \\
\hline
\end{tabular}

The discrete estimate then changes into the integral function as per the following equation when $\rho\left(x^{\prime}\right) d x^{\prime}$ which is the differential mass accepts the summation of neighboring particles and the $i$ itself.

$$
\langle f(x)\rangle=\int f\left(x^{\prime}\right) W\left(\frac{\left|x-x^{\prime}\right|}{h}\right) d x^{\prime}
$$

where $\left(x-x^{\prime}\right)$ is the distance between the particle of evaluation $x$ and arbitrary particle $x^{\prime}$.

Meanwhile, the conservation equation of continuum mechanics is determined as per the following equation.

$$
\frac{d \rho}{d t}=\rho \nabla \cdot U, \frac{d U}{d t}=\frac{1}{\rho} \nabla \cdot \sigma, \frac{d E}{d t}=\frac{1}{\rho} \sigma: \nabla \otimes U
$$

where $d x / d t=U ; \rho$ is the scalar density; $E$ is the specific energy; $U$ is the velocity vector; and $\sigma$ is the stress tensor (dependent variables). Meanwhile, the independent variables are spatial position, $x$ and time.

\section{SPH MODEL}

The impact of CS particles has been modelled using $\mathrm{SPH}$, which is a mesh-free adaptive Lagrangian particle method. This numerical technique uses smoothed particles instead of a mesh as the interpolation points to represent materials at discrete locations. Aluminum has been chosen as the particle, whereas aluminum, titanium and magnesium have been chosen as the substrate materials for multiple particle impact. The impact behaviour of aluminum particles on different substrates has been studied using titanium and magnesium as the substrates, due to their heavier and lighter nature compared to aluminum particles, respectively.

The particle velocity of multiple particle simulations for HPCS and LPCS is set at $800 \mathrm{~m} / \mathrm{s}$ and $400 \mathrm{~m} / \mathrm{s}$, respectively. Particle velocity of $800 \mathrm{~m} / \mathrm{s}$ has been chosen for HPCS due to it being the optimum velocity and providing the highest deposition efficiency (Yusof et al. 2014). Meanwhile, the velocity of $400 \mathrm{~m} / \mathrm{s}$ has been selected in this study as any velocity above the critical 
velocity of $300 \mathrm{~m} / \mathrm{s}$ can be deposited on the substrate (Ogawa et al. 2008). All particle sizes are set at $25 \mu \mathrm{m}$, while the initial temperature for the particle and substrate for both processes are assumed to be at room temperature $(300 \mathrm{~K})$

\section{MATERIAL MODEL}

The material model described by Johnson Cook plasticity model and the state of equation for aluminum, titanium and magnesium both have been obtained from previous studies (Manap et al. 2018; Schmidt et al. 2006). In this work, the model utilized uses strain, strain rate and temperature dependent formulation for stress flow as in the following equation.

$$
\sigma=\left[A+B \varepsilon_{p}^{n}\right]\left[1+C \ln \left(\frac{\varepsilon_{p}}{\varepsilon_{n}}\right)\right]\left[T-\left(T^{*}\right)^{m}\right]
$$

where $\sigma$ is the equivalent flow stress; $\dot{\varepsilon_{n}}$ and $\dot{\varepsilon_{p}}$ are the equivalent plastic strain and strain rate, respectively; and $\dot{\varepsilon_{0}}$ is the normalizing reference strain rate. Meanwhile, material parameter $A, B, C, n$ and $m$ are specific parameters, where $A$ is the yield stress in a compression test, $B$ is the strain hardening parameters and $C$ is the strain-rate hardening coefficient, whilst $n$ and $m$ are the power exponent for strain hardening and thermal-softening terms, respectively.

Furthermore, the dimension-less temperature is described as in the following equation.

$$
T^{*}=\left(T-T_{r e f}\right) /\left(T_{m e l t}-T_{r e f}\right)
$$

where $T_{\text {ref }}$ and $T_{\text {melt }}$ is the reference temperature and melting temperature, respectively. The melting temperature is determined based on the state of the material and the hardening effect.

\section{RESULTS AND DISCUSSION}

\section{IMPACT BEHAVIOUR OF ALUMINUM MULTIPLE PARTICLE ON ALUMINUM SUBSTRATE}

The deformation behaviour of aluminum multiple particle impact on the aluminum substrate using HPCS and LPCS is shown in Figure 1(a) and 1(b), respectively. It is worth noting that the powder particles at the bottom (Label 1) of the coating for both HPCS and LPCS are fully deformed, indicating an intensive deformation. The shape of the spherical particles at the bottom has changed to lens shape, deeply penetrating into the substrate after the impact. It is clear that the metal jets are formed at the edge of each particle. In contrast, the powder particles at the top (Label 2) are more deformed in HPCS deposition compared to LPCS. Moreover, the temperature contours obtained for both processes have also differed. The maximum temperature for LPCS deposition is lower compared to HPCS deposition, which is $540 \mathrm{~K}$ and 640 $\mathrm{K}$ respectively.

Figure 2 displays the flattening ratio $\left(R_{f}\right)$ of the multiple particle impact of aluminum powder on aluminum substrate using HPCS and LPCS, in investigating the impact behaviour of the particles in detail. To analyze particle deformation to a certain extent, $R_{f}$ is used according to the definition in thermal spraying as per the following equation.

$$
R_{f}=\frac{D}{d_{p}}
$$

where $D$ is the spreading diameter of the flattened particle, whilst $d_{p}$ is the initial particle diameter.

From Figure 2, the flattening ratio between particles at the bottom and at the top for HPCS and LPCS is different. The flattening ratio of HPCS at the bottom has displayed the highest value around 1.46, compared to 1.24 for LPCS. Meanwhile, the flattening ratio of the particle at the top for HPCS and LPCS are 1.16 and 1.14, respectively. The $R_{f}$ value of the bottom particle is higher than that of the top for both HPCS and LPCS, which is due the intensive deformation travelled from the top particle. In contrast, the top particle has a lower $R_{f}$ value as it did not experience impact from any particle above it, being the top particle. Therefore, this result denotes that the cold spray method with higher velocity (HPCS; $800 \mathrm{~m} / \mathrm{s}$ ) gives greater impact compared to the lower velocity (LPCS; $400 \mathrm{~m} / \mathrm{s}$ ).

Furthermore, the gap of the flattening ratio between particles at the bottom and at the top is 0.3 and 0.1 for HPCS and LPCS, respectively. The gap is larger in case of HPCS due to the greater impact, whereas the lower gap for LPCS is caused by the subsequent low velocity impact from powder particles at the top, which formed a denser coating. This result is indicative of the deformation of the deposited powder particles, which becomes increasingly intensive due to the subsequent impact of powder particles from the top. This may cause the powder particles at the bottom of the coating to obtain a good bond. The obtained result is in good agreement with the previous study by Yin et al. (2009). This work has claimed that the interaction between particles plays an important role in particle deformation, affecting the coating formation (Yin et al. 2009). Therefore, subsequent particles create a denser coating with better bond formation during impact. 


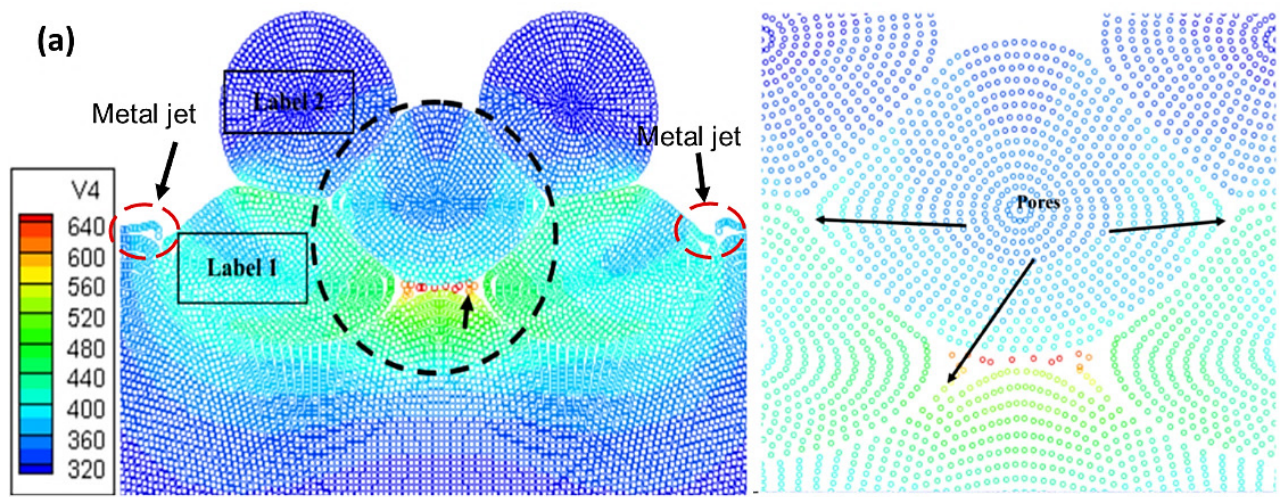

(b)

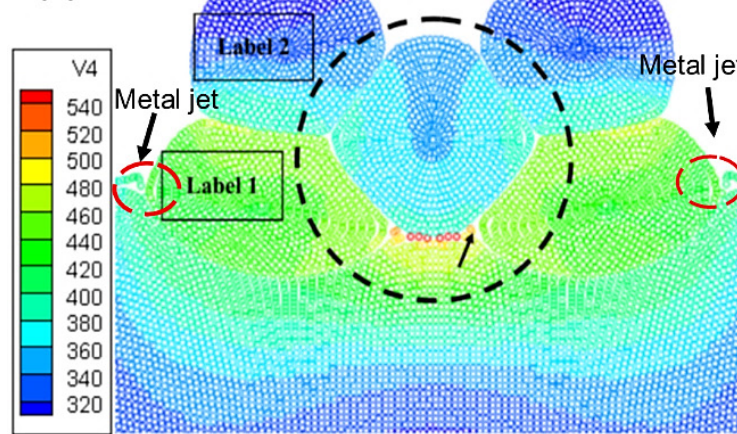

10\%

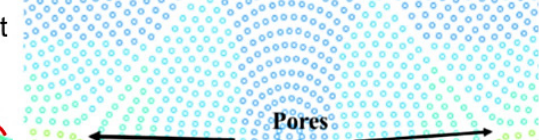

FIGURE 1. Deformation patterns and temperature contours of aluminum particles on aluminum substrate using (a) HPCS and (b) LPCS

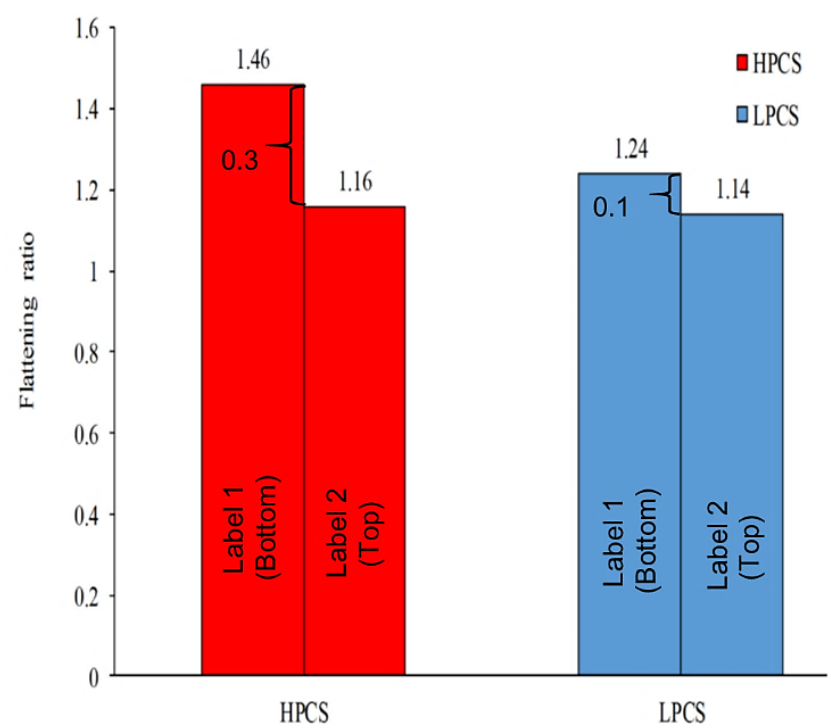

FIGURE 2. Flattening ratio of aluminum particles on aluminum substrate using HPCS and LPCS 
In Figure 3(a), the temporal development of total energy (i.e. kinetic energy and internal energy) of the multiple particle impact of the aluminum powder on the aluminum substrate prepared by HPCS and LPCS are depicted accordingly. The total energy of both processes has reduced quickly during the initial impact as most of the energy has been transferred to the substrate, while some dissipated as heat, with corresponding temperature rise seen at the deformed areas. Moreover, the total energy has also started to increase on further impact at $17 \mathrm{ns,}$ which is obtained by gaining energy from the subsequent impact of powder particles at the top. HPCS has yielded the highest total energy as it gained greater energy from the high velocity impact from the top particle, which has caused intensive deformation (Luo et al. 2014; Ning et al. 2008).

Next, the maximum temperature of HPCS and LPCS also differs at the deformed areas. Time history of the maximum temperature for the multiple particle impact of the aluminum powder on the aluminum substrate is shown in Figure 3(b). The maximum temperature obtained by HPCS and LPCS is $640 \mathrm{~K}$ and $540 \mathrm{~K}$, respectively. Generally, high maximum temperature occurs at the largest deformation, with consequent high impact and large flattening ratio (Kamaraj \& Radhakrishnan 2019). Thus, HPCS has obtained a higher maximum temperature compared to LPCS.
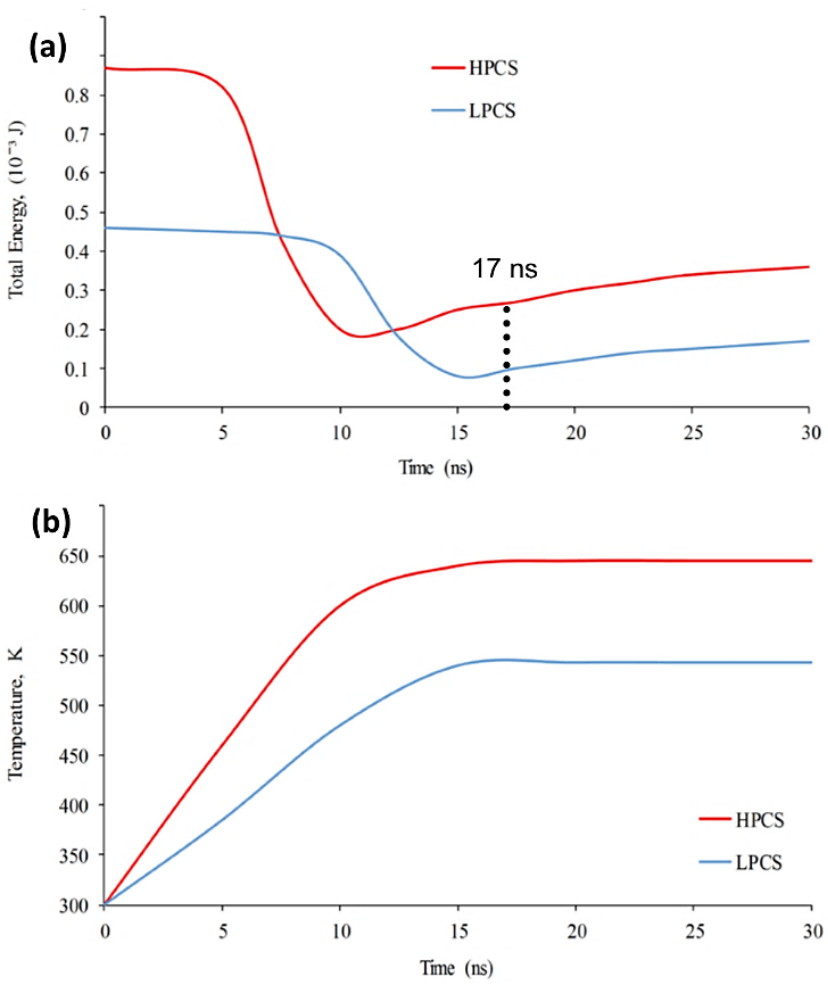

FIGURE 3. (a) Temporal development of total energy and (b) time history of the maximum temperature of aluminum particle on aluminum substrate using HPCS and LPCS

Moreover, HPCS has also exhibited higher porosity than LPCS. This can be observed in the magnified view of Figure 1, where the powder particles are fully deformed at the bottom. Larger pores are also formed between these particles, which are due to the subsequent high velocity impact from the top particles. In addition, the larger gap of flattening ratio between particles at the bottom and top of HPCS observed in Figure 2 also leads to greater porosity.

In contrast, LPCS has exhibited lower porosity, where the powder particles at the bottom are not fully deformed. Therefore, the subsequent low velocity impact from the powder particles at the top has resulted in smaller pores formed between these particles (Figure 
1(b)). The smaller gap of flattening ratio between particles at the bottom and top as observed in Figure 2 is also the cause of pore formation reduction, creating a denser coating. According to Lee et al. (2008), aluminum coating deposited using LPCS method has displayed higher hardness due to the peening effect.

Therefore, the results obtained have indicated that the impact of aluminum-on-aluminum substrate using HPCS deposition method has yielded a larger $R_{f}$ value, high total energy and high maximum temperature. This results in greater pore formation between particles, which leads to poor quality of coating. Hence, LPCS is better as an aluminum deposition method compared to HPCS.

\section{IMPACT BEHAVIOUR OF ALUMINUM MULTIPLE PARTICLES ON DIFFERENT SUBSTRATES}

Figure 4 shows the deformation behaviour of aluminum multiple particles impacting on titanium and magnesium substrates, using HPCS and LPCS. The obtained deformation behaviour varied from the deformation behaviour impacting on aluminum substrate as seen in Figure 1.
The particles deposited on the titanium substrate using HPCS (Figure 4(a)) are observed to be deformed with a deep notch. Furthermore, the spherical powder particle shape at the bottom (Label 1) has changed to a discoidal shape after the impact. In addition, extensive deformation has occurred at the contact area, causing complete deposition onto the titanium substrate as observed at Label 1 in Figure 4(a). Metal jets have also formed at the edge of particles. In contrast, more deformation is seen in Figure 4(b) for the magnesium substrate compared to the particles using HPCS. This is due to greater energy dissipation occurring in the substrate, as magnesium substrate is lighter than the aluminum particles. Thus, the aluminum particles deposited on the magnesium substrate has experienced a slight deformation only as most of the energy has dissipated into the substrate (Shayegan et al. 2014).

Furthermore, particles deposited on titanium substrate using LPCS (Figure 4(c)) has also displayed slight deformation, without the formation of metal jet at their edge. Meanwhile, particles deposited on the magnesium substrate using LPCS (Figure 4(d)) are slightly deformed whereas there is a large indentation in the substrate.
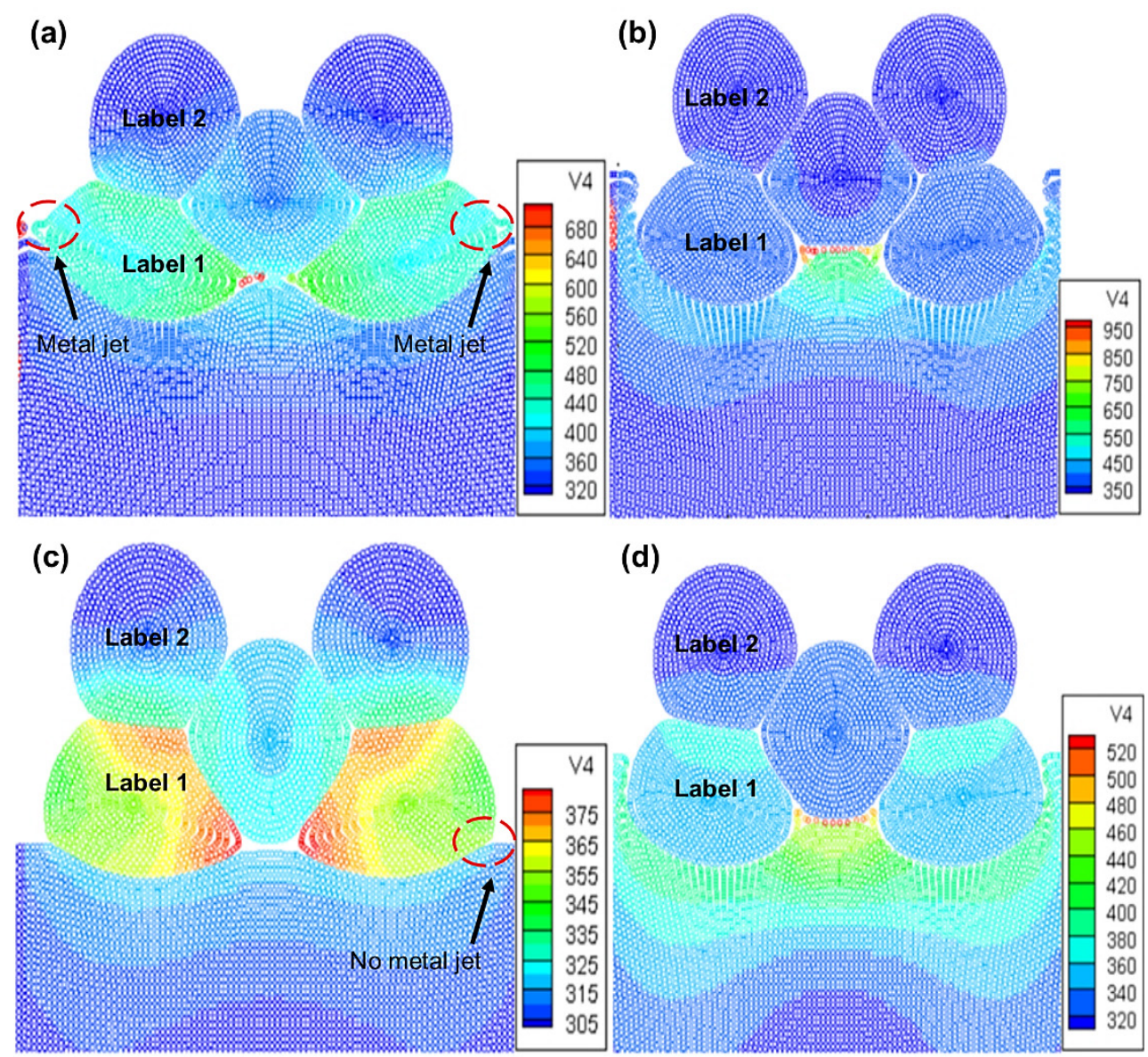

FIGURE 4. Deformation patterns and temperature contours of aluminum particles on (a, c) titanium, and (b, d) magnesium substrates using HPCS

$(\mathrm{a}, \mathrm{b})$ and LPCs (c, d) 
The overall simulation results have demonstrated that a larger deformation can be observed on the particles impacting on titanium substrate, in comparison to the magnesium substrate due to the relatively light weight and low hardness of magnesium (Czerwinski 2008). According to previous works (Yin et al. 2018; Yin et al. 2014), the impact variation on different substrates observed via the obtained results is attributable to the distinct weight and hardness of the materials. This statement is subsequently proven in the following explanation on titanium and magnesium materials, specifically their weight and hardness.

The aluminum particles impacting on titanium substrate has resulted in greater particle deformation as almost all of the kinetic energy has dissipated into the aluminum particles. This is due to titanium being heavier and harder than aluminum, as evidenced by the titanium substrate showing difficult deformation processes as seen in Figure 4(a) and Figure 4(c). In contrast, magnesium is lighter and less hard than the aluminum particles, causing a greater deformation in the substrate. The kinetic energy from the subsequent impact of the top particle (Label 2) has partly contributed to the deep indentation on the magnesium substrate, thus causing the particles to be trapped by the substrate at the contact area. Consequently, this event is indicative of a good bonding between the particles and the substrate.

Moreover, previous literature (Christoulis et al. 2011; Gao et al. 2008; Yin et al. 2012) have shown similar results, whereby the substrates have difficulties to undergo deformation when using heavyweight and hard substrate materials. Thus, the type of substrates used to deposit aluminum particles also plays a major role in studying the impact behaviour on particle deposition.

Figure 5 shows the flattening ratio of the aluminum multiple particle impacting on aluminum (aluminum/aluminum), titanium (aluminum/titanium), and magnesium (aluminum/magnesium) substrates, respectively. The aluminum multiple particles on the bottom impacting on titanium substrate, in particular, has the highest value of flattening ratio at $1.6 \mathrm{using}$ HPCS, followed by aluminum/aluminum. Meanwhile, the impact on aluminum/magnesium has displayed the lowest value of $R_{f}$, with 1.2 and 1.11 for bottom particles using HPCS and LPCS, respectively.

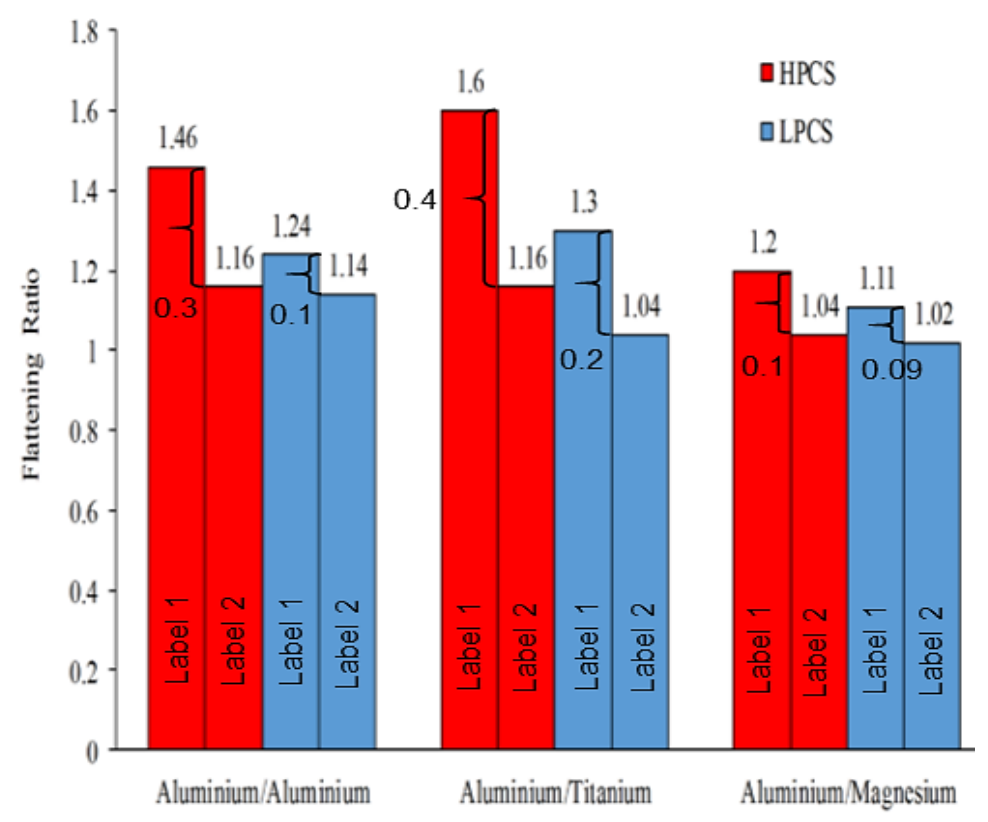

FIGURE 5. Flattening ratio of aluminum particles on aluminum, titanium, and magnesium substrates using HPCS and LPCS

The particles at the top have not shown prominent differences of $R_{f}$ values among the three types of substrates. This is due to the lack of further impact from other particles above it, as it is positioned at the top. Furthermore, as mentioned earlier, the larger gap between the top and bottom particle has resulted in a poor coating 
due to a greater amount of pore formation. Aluminum particles deposited on magnesium substrate specifically has exhibited the smallest gap of 0.09 using LPCS. This is due to magnesium being lighter and less hard compared to aluminum, as well as LPCS exerting a low velocity deposition (Yin et al. 2012).

Then, Figure 6(a) and 6(c) shows the total energy of the aluminum multiple particle impact on the aluminum, titanium and magnesium substrates using HPCS and LPCS. Overall, aluminum particles deposited on different substrates have gained more energy using HPCS than LPCS. The aluminum/magnesium specifically has gained the highest total energy, followed by aluminum/titanium and aluminum/aluminum via HPCS. The high total energy experienced by the particles impacting on magnesium substrate has exerted deep indentation in the substrate, as observed in Figure 6(a) and 6(c).

Meanwhile, the aluminum particles deposited on aluminum substrate using LPCS has yielded the highest total energy, followed by aluminum/magnesium and aluminum/titanium, as seen in Figure 6(c). The results indicate that different weights and hardness of substrates can influence the amount of total energy gained during the deposition process (Jodoin et al. 2006).

Figure 6(b) and 6(d) shows the time history of the maximum temperature for multiple particle impact of aluminum powder on the aluminum, titanium, and magnesium substrates, respectively, using HPCS and LPCS. The aluminum/magnesium has exhibited the highest maximum temperature for HPCS, followed by aluminum/titanium and aluminum/aluminum. This allows the substrate to be softer and allowing easier penetration of the particles deeply into the substrate, thus causing a deep indentation in magnesium substrates, compared to the titanium substrates. Aluminum particle impacting on aluminum substrate has also shown the least total energy and maximum temperature (Figure 6(a) and 6(b)) using HPCS. This proves that HPCS poses a difficult application in the context of aluminum repair (Lee et al. 2007).

On the contrary, the aluminum/aluminum has exhibited the highest maximum temperature for LPCS, followed by aluminum/magnesium and aluminum/ titanium. This is indicative of the process accommodating well in repairing aluminum components. In contrast, aluminum/titanium yielding the lowest total energy and maximum temperature (Figure 6(c) and 6(d)) has proven that LPCS is limited to light and less hard components.

Substrates that are lighter and less hard than the particles can gain more total energy and attain a high maximum temperature. Thus, magnesium substrate, which is lighter and less hard than aluminum particle, has achieved a higher total energy and maximum temperature compared to titanium substrate (heavy and harder than aluminum particle) for both HPCS and LPCS. In contrast, the aluminum substrate has gained the least total energy and maximum temperature for HPCS, whereas it yielded the highest total energy and maximum temperature for LPCS.
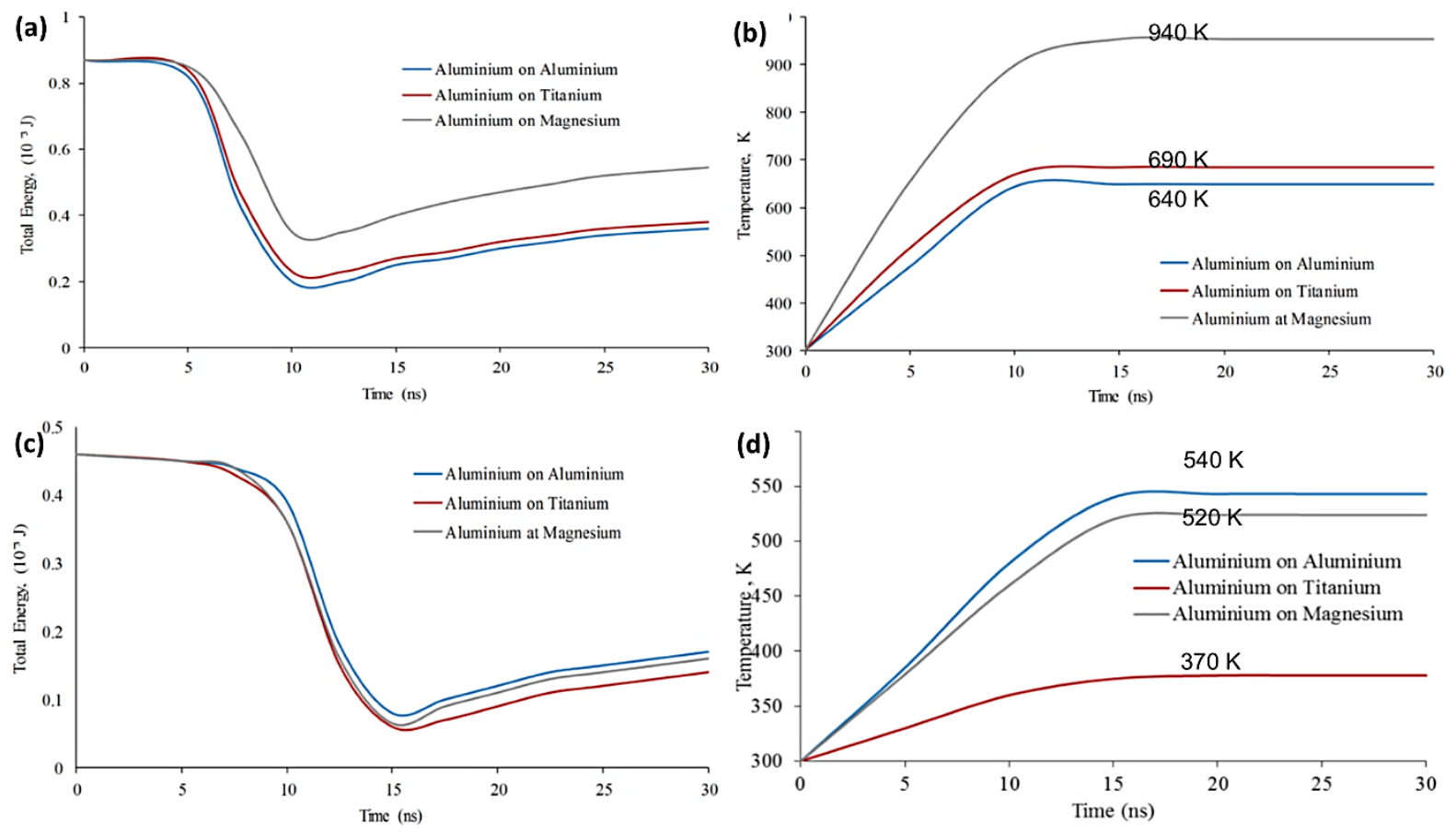

FIGURE 6. $(\mathrm{a}, \mathrm{c})$ Temporal development of total energy and $(\mathrm{b}, \mathrm{c})$ time history of the maximum temperature of aluminum particles on aluminum, titanium and magnesium substrates using $(a, b)$ HPCS and (c, d) LPCS 
The contrasting results obtained by HPCS and LPCS, respectively, for aluminum/aluminum is attributable to the different velocity impact experienced by the particles. As the particle and substrate are of the same type (aluminum/aluminum), they are purely dependent on the deposition velocity instead of the weight and hardness of the material. According to the study conducted by Yin et al. (2009), the deposition of particles with the greater velocity (HPCS) causes more particle deformation via greater total energy and maximum temperature. Hence, aluminum/aluminum when utilizing HPCS has attained a greater total energy and maximum temperature than LPCS, causing severe deformation in the particles and resulting in poor coating effect.

As aluminum/aluminum is independent towards weight and hardness, it is used as a reference in Figure 6. Titanium substrate, in particular, has gained more total energy and maximum temperature than aluminum substrate when using HPCS. Meanwhile, aluminum substrate has gained more total energy and maximum temperature rather than magnesium and titanium substrates via LPCS. This can be explained by LPCS providing an insufficient amount of velocity to allow the particles to deform extensively on heavier and harder substrates. HPCS, in turn, provides higher total energy and increased temperature by dissipating almost all of the kinetic energy into the heavier and harder substrate, causing severe substrate deformation (Novoselova et al. 2006).

\section{EFFECT OF COATING PROCESS ON RELIEVING THE RESIDUAL STRESS}

Figure 7(a) presents the comparison of the throughthickness residual stress measured in the aluminum substrate using HPCS and LPCS. The residual stress of HPCS has increased rapidly from $-100 \mathrm{MPa}$ at the depth of $10 \mu \mathrm{m}$ to $145 \mathrm{MPa}$ at $60 \mu \mathrm{m}$, which changes from compressive stress to tensile stress. In contrast, LPCS has resulted in compressive stress, at the respective values of -145 and $-265 \mathrm{MPa}$ at the depth of 10 and 60 $\mu \mathrm{m}$ accordingly.

Therefore, HPCS has exhibited a greater residual stress than LPCS, as the high particle velocities exert greater kinetic energy and cause large deformation in the particles. The large deformation then leads to the high amount of stress relieved in the substrates by HPCS specifically. Furthermore, previous work of Gelichi et al. (2014), has served as a reference in comparing the outcomes obtained by LPCS, as the same velocity of 400 $\mathrm{m} / \mathrm{s}$ has been utilized as in LPCS. The obtained residual stress for LPCS is almost similar to the result obtained by Gelichi et al. (2014). Besides that, the stress has changed to compressive stress at a greater depth, which is due to the large peening effect of the aluminum impacting on the substrate. Generally, compressive stress is known to induce good coating deposition and deposition performance (Gilmore et al. 1999).
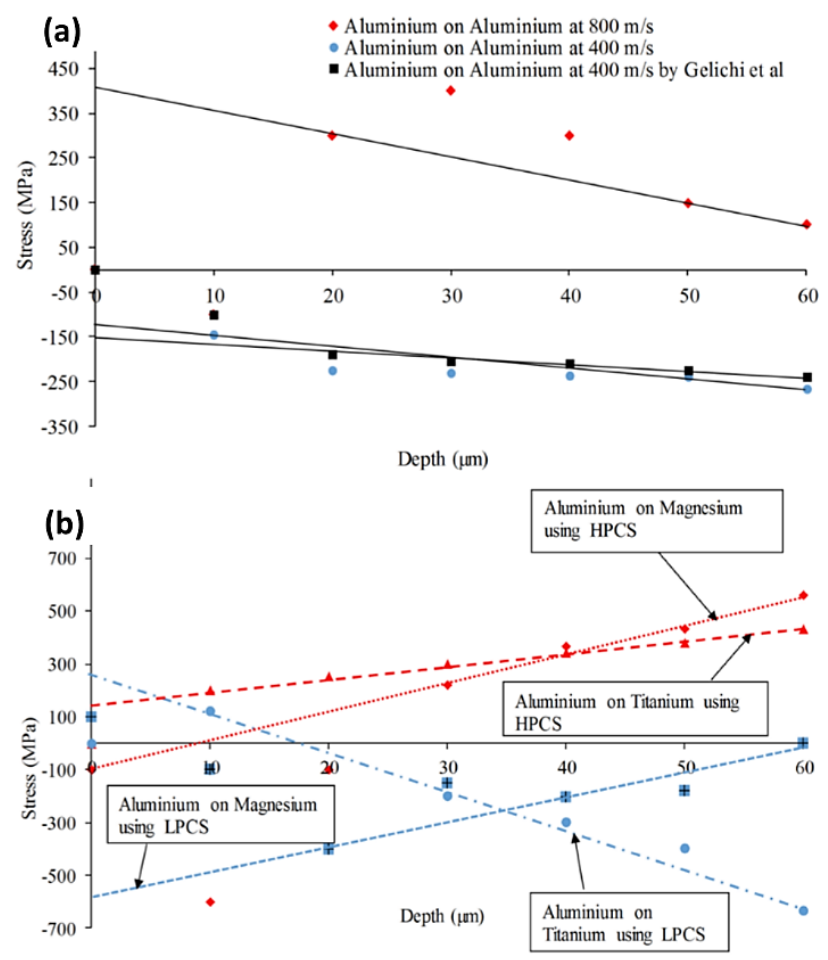

FIGURE 7. The comparison of the through-thickness residual stress measured in (a) aluminum substrate and (b) titanium and magnesium substrate using HPCS and LPCS 
In Figure 7(b), a comparison has been made regarding the residual stress measured for aluminum impacting on aluminum, titanium and magnesium substrates using HPCS and LPCS accordingly. The residual stress for aluminum impacting on titanium substrate using HPCS has started from $200 \mathrm{MPa}$ at the depth of $10 \mu \mathrm{m}$ before reaching its maximum tensile stress of $431 \mathrm{MPa}$ at the depth of $60 \mu \mathrm{m}$. Meanwhile, the stress for aluminum impacting on magnesium substrate using HPCS has also increased rapidly, changing from compressive stress below $-500 \mathrm{MPa}$ at the depth of 10 $\mu \mathrm{m}$ to maximum tensile stress of $560 \mathrm{MPa}$ at the depth of $60 \mu \mathrm{m}$.

In contrast, the stress for aluminum impacting on titanium substrate using LPCS has decreased significantly from the tensile stress of $110 \mathrm{MPa}$ at the depth of $10 \mu \mathrm{m}$ to the maximum compressive stress of $-600 \mathrm{MPa}$ at the depth of $60 \mu \mathrm{m}$. meanwhile, the stress for aluminum/ magnesium has revealed the compressive stress of -100 $\mathrm{MPa}$ at $10 \mu \mathrm{m}$ before changing to tensile stress of 50 MPa at $60 \mu \mathrm{m}$.

Therefore, the obtained results have indicated that other than different deposition methods, the types of substrates used to deposit particles can also influence the distribution of residual stresses (Spencer et al. 2012). Therefore, LPCS has been shown to experience compressive stress, whereas HPCS deposition experiences tensile stress. Compressive stress is known to ensure longer component lifetime due to their positive effect on the fatigue life and wear resistance application (Ghelichi et al. 2012; Saleh et al. 2014).

\section{CONCLUSION}

In summary, the impact behaviour and residual stress of different aluminum deposition methods (HPCS and LPCS) on various substrates have been carefully studied in this attempt. The aluminum particles impacting on aluminum substrates using HPCS have deformed intensively while displaying the highest flattening ratio. This leads to greater porosity formation between the particles and resulted in poor coating quality. Furthermore, magnesium and titanium substrates have gained more total energy and maximum temperature than aluminum substrate when using HPCS. In contrast, aluminum substrate has gained more total energy and maximum temperature than magnesium and titanium substrates by using LPCS. This is attributable to LPCS providing an insufficient amount of velocity to allow the particles to deform extensively on heavier and hard substrates. HPCS has provided a higher total energy and increased temperature, achieved by dissipating almost all of the kinetic energy into the lighter and less hard substrate, and subsequently caused severe deformation in the substrate. Hence, the results denote that HPCS contributes well to particle deposition on heavy and harder substrates, while LPCS favors particle deposition on light and less hard substrates. In terms of residual stress, LPCS deposition experiences compressive stress, whereas HPCS deposition experiences tensile stress. Compressive stress ensures a longer component lifetime due to its positive effect on the fatigue life and wear resistance application. Thus, the overall results indicate that LPCS is a better option for aluminum deposition at a low velocity.

\section{ACKNOWLEDGEMENTS}

The authors would like to thank the Ministry of Higher Education Malaysia (MoHE) under the Fundamental Research Grant Scheme (FRGS) of Grant No. FRGS20130108, and Universiti Tenaga Nasional (UNITEN) for funding this study.

\section{REFERENCES}

Andreatta, F., Terryn, H. \& de Wit, J.H. 2004. Corrosion behaviour of different tempers of aa7075 aluminium alloy. Electrochimica Acta 49(17-18): 2851-2862.

Attia, H., Meshreki, M., Korashy, A., Thomson, V. \& Chung, V. 2011. Fretting wear characteristics of cold gas-dynamic sprayed aluminum alloys. Tribology International 44(11): 1407-1416.

Bahmani, A., Arthanari, S. \& Shin, K.S. 2019. Improved corrosion resistant and strength of a magnesium aloy using multi-directional forging (MDF). International Journal of Advanced Manufacturing Technology 105(1-4): 785-797.

Blindheim, J., Welo, T. \& Steinert, M. 2019. First demonstration of a new additive manufacturing process based on metal extrusion and solid-state bonding. International Journal of Advanced Manufacturing Technology 105(5-6): 2523-2530.

Champagne, V. \& Helfritch, D. 2016. The unique abilities of cold spray deposition. International Materials Reviews 61(7): 437-455

Christoulis, D.K., Guetta, S., Guipont, V. \& Jeandin, M. 2011. The influence of the substrate on the deposition of cold-sprayed titanium: An experimental and numerical study. Journal of Thermal Spray Technology 20(3): 523-533.

Czerwinski, F. 2008. Magnesium Injection Molding. Boston: Springer.

Dong, H. 2010. Surface Engineering of Light Alloys: Aluminium, Magnesium and Titanium Alloys. New York: Woodhead Publishing Limited.

Dzhurinskiy, D., Maeva, E., Leshchinsky, \& Maev, R.G. 2012. Corrosion protection of light alloys using low pressure cold spray. Journal of Thermal Spray Technology 21(2): 304-313. 
Gao, P.H., Li, C.J., Yang, G.J., Li, Y.G. \& Li, C.X. 2008. Influence of substrate hardness on deposition behaviour of single porous WC-12Co particle in cold spraying. Surface and Coatings Technology 203(3-4): 384-390.

Ghelichi, R., Bagherifard, S., MacDonald, D., Brochu, M., Jahed, H., Jodoin, B. \& Guagliano, M. 2014. Fatigue strength of Al alloy cold sprayed with nanocrystalline powders. International Journal of Fatigue 65: 51-57.

Ghelichi, R., MacDonald, D., Bagherifard, S., Jahed, H., Guagliano, M. \& Jodoin, B. 2012. Microstructure and fatigue behaviour of cold spray coated A15052. Acta Materialia 60(19): 6555-6561.

Gilmore, D.L., Dykhuizen, R.C., Neiser, R.A., Roemer, T.J. \& Smith, M.F. 1999. Particle velocity and deposition efficiency in the cold spray process. Journal of Thermal Spray Technology 8(4): 576-582.

Houghton, J.E.T., Ding, Y., Griggs, D.J., Noguer, M., van der Linden, P., Dai, X., Maskell, M. \& Johnson, C.A. 2001. Climate Change 2001: The Scientific Basis. United Kingdom and New York: Cambridge University Press.

Jodoin, B., Ajdelsztajn, L., Sansoucy, E., Zúñiga, A., Richer, P. \& Lavernia, E.J. 2006. Effect of particle size, morphology, and hardness on cold gas dynamic sprayed aluminum alloy coatings. Surface and Coatings Technology 201(6): 34223429.

Kamaraj, M. \& Radhakrishnan, V.M. 2019. Cold spray coating diagram: bonding properties and construction methodology. Journal of Thermal Spray Technology 28(4): 756-768.

Lee, H., Shin, H., Le, S. \& Ko, K. 2008. Effect of gas pressure on Al coatings by cold gas dynamic spray. Materials Letters 62(10-11): 1579-1581.

Lee, J.C., Kang, H.J., Chu, W.S. \& Ahn, S.H. 2007. Repair of damaged mold surface by cold-spray method. CIRP Annals 56(1): 577-580.

Luo, X.T., Li, C.X., Shang, F.L., Yang, G.J., Wang, Y.Y. \& Li, C.J. 2014. High velocity impact induced microstructure evolution during deposition of cold spray coatings: A review. Surface and Coatings Technology 254: 11-20.

Manap, A., Okabe, T., Ogawa, K., Mahalingam, S. \& Abdullah, H. 2019. Experimental and smoothed particle hydrodynamics analysis of interfacial bonding between aluminum powder particles and aluminum substrate by cold spray technique. International Journal of Advanced Manufacturing Technology 103(9-12): 4519-4527.

Manap, A., Yusof, S.N., Afandi, N.F. \& Mahalingam, S. 2018. Impact behaviour of lightweight metal component repair using aluminium particles with high pressure cold spray process and low-pressure cold spray process. Proceedings of Mechanical Engineering Research Day 2018: 57-58.

Manap, A., Yusof, S.N., Afandi, N.F., Mahalingam, S., Rosli, Z.M. \& Ogawa, K. 2018. Mechanical and wear properties of aluminium coatings produced by high pressure and lowpressure cold sprayed processes. In Proceedings of Asia International Conference on Tribology 2018. Malaysian Tribology Society. pp. 215-216.
Ning, X.J., Jang, J.H., Kim, H.J., Li, C.J. \& Lee, C. 2008. Cold spraying of Al-Sn binary alloy: Coating characteristics and particle bonding features. Surface and Coatings Technology 202(9): 1681-1687.

Novoselova, T., Fox, P., Morgan, R. \& O’Neill, W. 2006. Experimental study of titanium/aluminium deposits produced by cold gas dynamic spray. Surface and Coatings Technology 200(8): 2775-2783.

Ogawa, K., Ito, K., Ichimura, K., Ichikawa, Y., Ohno, S. \& Onda, N. 2008. Characterization of low-pressure cold-sprayed aluminum coatings. Journal of Thermal Spray Technology 17(5-6): 728-735.

Saleh, M., Luzin, V. \& Spencer, K. 2014. Analysis of the residual stress and bonding mechanism in the cold spray technique using experimental and numerical methods. Surface and Coatings Technology 252: 15-28.

Schmidt, T., Gärtner, F., Assadi, H. \& Kreye, H. 2006. Development of a generalized parameter window for cold spray deposition. Acta Materilia 54(3): 729-742.

Shayegan, G., Mahmoudi, H., Ghelichi, R., Villafuerte, J., Wang, J., Guagliano, M. \& Jahed, H. 2014. Residual stress induced by cold spray coating of magnesium AZ31B extrusion. Materials \& Design 60: 72-84.

Spencer, K., Luzin, V., Matthews, N. \& Zhang, M. 2012. Residual stresses in cold spray Al coatings: The effect of alloying and of process parameters. Surface and Coatings Technology 206(19-20): 4249-4255.

Wong, W., Vo, P., Irissou, E., Ryabinin, A.N., Legoux, J.G. \& Yue, S. 2013. Effect of particle morphology and size distribution on cold-sprayed pure titanium coatings. Journal of Thermal Spray Technology 22(7): 1140-1153.

Yin, S., Cavaliere, P., Aldwell, B., Jenkins, R., Liao, H., Li, W. \& Lupoi, R. 2018. Cold spray additive manufacturing and repair: Fundamentals and applications. Additive Manufacturing 21: 628-650

Yin, S., Suo, X., Su, J., Guo, Z., Liao, H. \& Wang, X. 2014. Effects of substrate hardness and spray angle on the deposition behaviour of cold-sprayed Ti particles. Journal of Thermal Spray Technology 23(1-2): 76-83.

Yin, S., Wang, X., Li, W., Lioa, H. \& Jie, H. 2012. Deformation behaviour of the oxide film on the surface of cold sprayed powder particle. Applied Surface Science 259: 294-300.

Yin, S., Wang, X., Li, W. \& Xu, B.P. 2009. Numerical investigation on effects of interactions between particles on coating formation in cold spraying. Journal of Thermal Spray Technology 18(4): 686.

Yusof, S.N.A., Manap, A., Misran, H. \& Othman, S.Z. 2014. Computational analysis of single and multiple impacts of low pressure and high pressure cold sprayed aluminum particles using SPH. Advanced Materials Research 974: 147-151.

Abreeza Manap* \& Savisha Mahalingam

Institute of Sustainable Energy

Universiti Tenaga Nasional

Jalan IKRAM-UNITEN

43000 Kajang, Selangor Darul Ehsan

Malaysia 
Abreeza Manap*, Siti Nurul Akmal Yusof \& Nurfanizan Afandi Department of Mechanical Engineering

Universiti Tenaga Nasional

Jalan IKRAM-UNITEN

43000 Kajang, Selangor Darul Ehsan

Malaysia

Huda Abdullah

Department of Electrical Electronic and System Engineering Faculty of Engineering and Built Environment

Universiti Kebangsaan Malaysia

43600 UKM Bangi, Selangor Darul Ehsan

Malaysia
*Corresponding author; email: Abreeza@uniten.edu.my

Received: 9 December 2020

Accepted: 18 July 2021 